\title{
Comprehensive characterization and material modeling for ceramic injection molding simulation performance validations
}

Tosello, Guido; Marhöfer, David Maximilian; Islam, Aminul; Müller, Tobias; Plewa, Klaus; Piotter, Volker

Published in:

International Journal of Advanced Manufacturing Technology

Link to article, DOI:

$10.1007 / \mathrm{s} 00170-018-03251-3$

Publication date:

2019

Document Version

Peer reviewed version

Link back to DTU Orbit

Citation (APA):

Tosello, G., Marhöfer, D. M., Islam, A., Müller, T., Plewa, K., \& Piotter, V. (2019). Comprehensive characterization and material modeling for ceramic injection molding simulation performance validations. International Journal of Advanced Manufacturing Technology, 102, 225-240. https://doi.org/10.1007/s00170018-03251-3

\section{General rights}

Copyright and moral rights for the publications made accessible in the public portal are retained by the authors and/or other copyright owners and it is a condition of accessing publications that users recognise and abide by the legal requirements associated with these rights.

- Users may download and print one copy of any publication from the public portal for the purpose of private study or research.

- You may not further distribute the material or use it for any profit-making activity or commercial gain

- You may freely distribute the URL identifying the publication in the public portal 


\section{Comprehensive characterization and material modelling for ceramic injection molding simulation performance validations}

Guido Tosello ${ }^{*}$ ) guto@mek.dtu.dk

David Maximilian Marhöfer ${ }^{2}$ maximilian.marhoefer@fhnw.ch

Aminul Islam¹ mais@mek.dtu.dk

Tobias Müller ${ }^{3}$ tobias.mueller2@kit.edu

Klaus Plewa ${ }^{4}$ klaus.plewa@kit.edu

Volker Piotter ${ }^{4}$ volker.piotter@kit.edu

\section{(*) Corresponding Author}

${ }^{1}$ Technical University of Denmark, Department for Mechanical Engineering Produktionstorvet, Building 427A, 2800 Kongens Lyngby, Denmark

2 University of Applied Sciences Northwestern Switzerland FHNW

School of Engineering, Institute of Polymer Nanotechnology

Klosterzelgstrasse 2, 5210 Windisch, Switzerland

${ }^{3}$ Karlsruhe Institute of Technology, Institute for Automation and Applied Informatics (IAI)

Hermann-von-Helmholtz-Platz 1, 76344 Eggenstein-Leopoldshafen, Germany

${ }^{4}$ Karlsruhe Institute of Technology, Institute for Applied Materials -

Materials Process Technology (IAM-WK)

Hermann-von-Helmholtz-Platz 1, 76344 Eggenstein-Leopoldshafen, Germany 


\section{ABSTRACT}

Powder injection molding is like the process of plastics injection molding capable of the mass production of highly functional complex 3D parts, just in ceramics and metals. The market for products made by powder injection molding is constantly growing. With this growth, the need for reliable process simulations arises. Simulation tools are widely used in the development of new products and are applied in powder and polymer injection molding to support the product design, shorten the development time, avoid errors, and help to optimize the mold and process design. However, material data for feedstocks and thus simulations of the powder injection molding process are hardly available yet. The present work introduces the necessary material data for establishing a material model for simulations. An extensive material characterization of ceramic feedstocks was conducted. The material investigations comprised the determination of basic, thermal, and rheological material properties to collect a comprehensive data set. The necessary measurements and tools are outlined and their results are discussed in detail with regards to powder content and in comparison to pure plastics. The gained data enabled to successfully create a material model for mold filling simulations. Powder injection molding experiments were carried out with a spiral test geometry. The mold was equipped with a sensor array for the process monitoring during injection. Furthermore, a simulation model of the test geometry was established. Finally, the results of the experiments and simulations are discussed and are compared to validate the performance of the simulations. The results showed the potential and limitations of process simulations and standard software applied in conventional and micro powder injection molding.

Keywords: powder injection molding, simulations, feedstocks, material characterization, rheology. 


\section{INTRODUCTION}

The process of ceramic injection molding emerged almost simultaneously with the wellknown process of plastic injection molding in the 1930s, the metal variant later in the 1970s [1]. Powder molding combines the superior properties of ceramics and metals compared to plastics like material strength, maximum service temperature with the advantages of injection molding such as medium to large-scale production, automation, and low costs. The process enables the fabrication of geometrically complex, threedimensional, and highly functional parts in ceramics and metals. Typical application fields of products made by powder injection molding are the automotive and aerospace industry, mechanical parts, the medical industry and health care, or consumer and industrial electronics. [1-4]

The used raw material, the so-called feedstock, is a mixture of an organic binder and the fine metal or ceramic powder. The binder provides the viscous properties and enables the feedstock to be used in injection molding. In addition, it is designed to maintain structural integrity of the solid part after the molding. The powder is made of the material from which the final product should actually be produced. $[1,5,6]$

The powder molding process is very similar to plastics injection molding, but the postprocessing steps of debinding and sintering are necessary to yield the final product. The process chain from raw material to final product can be described by the following phases $[1,2,7]$ : 
- compounding of the feedstock

- powder injection molding

- thermal, catalytic, or solvent-based debinding,

- sintering,

- possibly further post-processing for finishing or densification, e.g. políshing, hot isostatic pressing, annealing, or hardening.

Simulation tools are widely used in the development process of new products in the industry. Process simulations are an effective and important tool in order to assist and optimize the design of the new product or the actual manufacturing process. Also in the area of injection molding, simulations are proven to be precious tools. Hence, they are widely applied to accompany the product development from the first design of the plastic part to the finally fabricated mold $[1,8,9]$. In detail, the simulations are carried out for the same reasons as in other areas of engineering like [10-16]:

- to assist the product design at an early stage when molds are not available yet,

- to avoid costly design errors and necessary re-engineering,

- to shorten the development time and the time-to-market for a new product,

- to eliminate the need or reduce the amount of physical prototyping and experiments,

- to optimize the part and mold design as well as the parameter settings of the manufacturing process,

- to assist the material selection,

- to predict and improve the part quality (e.g. morphology and properties), 
- to gain a better understanding of the process characteristics especially the occurring shear rates which are the main reason for powder-binder-segregation which again cause dimensional inaccuracies and deformations.

Similar to many other engineering disciplines, process simulations of plastic and powder injection molding are based on the method of finite element analysis (FEA). Different software packages such as Autodesk Moldflow ${ }^{\circledR}$, Moldex3D $^{\circledR}$, or Sigmasoft ${ }^{\circledR}$ are commercially available on the market. Due to the complexity of the injection molding cycle and equipment, the increasing requirements on the part quality, and the quickly and steadily growing market for powder injection molding products, process simulations gain increasing importance.

However, there are two major problems with the simulation of powder injection molding. Firstly, the commercially available simulation software originates from the area of plastic injection molding. Yet, the feedstocks show significantly different properties than pure or even filled plastics $[3,17,18]$. The extensive powder content and the heavy powder weight compared to the lightweight polymer binder leads to a serious increase in inertia of the material flow. As a result, the powder feedstocks tend to jetting and wall slip. Moreover, powder-binder separation due to high shear rates can be sometimes observed leading to local differences in viscosity, powder content and hence shrinkage behavior while sintering. In addition, feedstocks exhibit significantly increased heat conductivity due to the metal and ceramic filler, but at the same time generally 
lower heat capacity than plastics. The different thermal properties lead to an increase of the heat loss, faster solidification of the melt which negatively influences filling and replication performance. Besides, the feedstocks have lower compressibility and lower temperature-dependent change in density. All the aforementioned effects are still subject to research and are usually not or insufficiently accounted for by commercial simulation tools. Continuous development and validation of the software is therefore crucial. $[3,5,18,19]$

Secondly, there is almost no material data and no material models of feedstocks available up till now. Additionally, guidelines or standards for the acquisition of such material data or for the application of simulations do not exist yet. Some material studies on feedstocks were reported within the last couple of years. Still, the investigations focus almost exclusively only on parts of all relevant material propertiesmostly either on the rheological or thermal aspects. $[8,18]$

This work is motivated by these problems. First, the lack of material data is tackled by running an extensive material characterization of two ceramic feedstocks. Basic properties like the density and powder content of the feedstocks and thermal properties such as the specific heat capacity and thermal conductivity were investigated. The rheological evaluation included the determination of the viscosity and pvT data. The aim was to outline all the necessary data. The collected material data was employed in creating a new material model. Moreover, this material model could be 
applied in the simulation of the powder injection molding process in order to conduct an assessment of the performance of state-of-the-art simulation software.

\section{THEORETICAL BACKGROUND}

\subsection{Necessary material data for simulations}

For the proper simulation of the injection molding process, a comprehensive set of material properties must be known. However, the required material properties depend on the type of simulation that is applied. The filling, packing, and cooling phase are governed by the flow of the plastic or feedstock. Therefore, the following properties are required [20]:

- viscosity,

- specific heat capacity

- thermal conductivity,

- no-flow temperature, glass transition, or melt temperature,

- $p v T$ data.

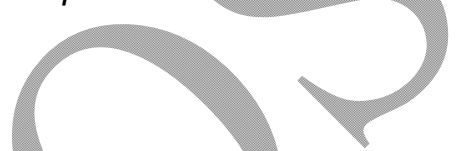

Simulations of the shrinkage and warpage of the molded part are governed by the mechanics of the material. Hence, the following properties are additionally required [20]

- elastic modulus,

- shear modulus,

- Poisson's ration,

- coefficient of thermal expansion. 


\subsection{Viscosity measurements}

\section{Viscosity models}

The advanced Cross model, default in many simulation software packages, is often used for mathematically describing the viscosity and the shear thinning effect of polymers.

This model describes the shear rate dependency of the viscosity over a wide range of shear rates very well, because it combines a Newtonian region at low shear rates with a power law shear thinning region at higher shear rates [20]. The viscosity $\eta$ is mathematically given by the Cross model as a function of the shear rate $\dot{\gamma}$ as

$$
\eta(\dot{\gamma})=\frac{\eta_{0}}{1+\left(\frac{\eta_{0} \dot{\gamma}}{\tau}\right)^{1-n}}
$$

where $\eta_{0}$ is the zero shear rate viscosity, $\tau$ is the shear stress, and $n$ the power-law index of the polymer. The term $1-n$ describes the slope of the viscosity curve in the power law region, when logarithmically plotted versus the shear rate.

In order to understand and simulate the flow of the polymer during the filling phase, the applied viscosity model must also account for the temperature changes happening during injection molding. The concept of time-temperature superposition can be applied to the viscosity. The core of the concept is to shift the known viscosity curve at a reference temperature along the time axis in order to gain the viscosity curve at any temperature different from the reference temperature. The shift factor is given by the Williams-Landel-Ferry (WLF) equation which can be also applied to the zero shear rate 
viscosity to introduce temperature dependency. This step yields the Cross-WLF model with the zero shear rate viscosity given as

$$
\eta_{0}=D_{1} \exp \left[\frac{-C_{1}^{0}\left(T-T_{0}\right)}{C_{2}^{0}+T-T_{0}}\right]
$$

where $D_{1}, C_{1}^{0}$, and $C_{2}^{0}$ are data-fitted constants, $T$ is the temperature, and $T_{0}$ is the reference temperature (often the glass transition temperature of the polymer).

Powder feedstocks can be understood as extremely filled plastics. In fact, the binder provides the viscous properties and acts as carrier for the rigid powder particles. The powder particles contribute though to a large extend of the volume of the feedstock. The feedstocks therefore show noticeably different flow properties compared to pure plastics. The powder particles influence the flow and viscosity because of the complex interaction between the binder and the particles. In contrast to the binder, they can be assumed as being incompressible and carry much more momentum owing to their weight. Furthermore, their size and shape affect the viscosity. As a consequence of these differences, the aforementioned models for the viscosity are often insufficient to describe the viscous nature of feedstocks properly.

The important Cross-WLF model with Herschel-Bulkley extension is based on the CrossWLF model. It accounts for the increase in viscosity and a Bingham-like behavior of the feedstocks at low shear rates $[18,21]$. In fact, the velocity profile of feedstocks, the socalled plug flow, looks more like an oblate parabola. This is due to the increase in viscosity in the center of the shear-governed fountain flow in injection molding [8]. The viscosity of the Herschel-Bulkley model is commonly given as [21] 


$$
\eta(\dot{\gamma})=\frac{\tau_{0}}{\dot{\gamma}}+m \dot{\gamma}^{n-1}
$$

where $\tau^{0}$ is the yield shear stress and $m$ is the consistency index.

\section{Mathematical corrections for measurements with capillary rheometers}

Capillary rheometers are commonly used to determine the viscosity of plastic and feedstock melts. However, the mathematical derivation of the viscosity from the measured pressure and flow rate assumes the following [21]:

- The flow is steady, isothermal, and laminar.

- There is no flow in radial or angular direction in the capillary.

- The plastic is incompressible.

However, these idealizing assumptions do not match to what is happening in reality. The viscosity data collected by means of a capillary rheometer should consequently be mathematically corrected. The following corrections can be relevant for processing the recorded viscosity data [22-25]:

- Bagley correction: the Bagley correction accounts for the entrance effects in the capillary rheometer. The measured pressure drop over the capillary is not only caused by the melt's flow resistance, but also by turbulent flow in the entrance region of the capillary. Besides, the melt must be accelerated from the low flow velocity in the reservoir to the high flow velocity in the capillary. Since plastics are viscoelastic materials, they temporarily absorb some of the applied pressure. 
This energy is again recovered after leaving the capillary and appears as an expansion of the material, the so-called die swell of the extrudate.

- Weissenberg-Rabinowitsch correction: the Weissenberg-Rabinowitsch correction compensates for the non-Newtonian (shear thinning) behavior of the plastics and computes the "real" shear stress at the wall of the capillary out of the "apparent" shear stress.

- Mooney correction: the Mooney correction is used to correct the velocity of the melt. Plastic melts do not always fulfill the assumption of no wall slip inside the capillary. In this case, the wall slip speed thus contributes apart from the melt velocity to the total flow rate.

- Dissipation correction: the dissipation correction is used, if the assumption of isothermal flow inside the capillary is not true anymore. At high shear rates, the melt might heat up due to internal friction and the resulting dissipative heating.

\subsection{Thermodynamics}

Besides the viscosity, information about the thermodynamic properties of the feedstocks is necessary for computer simulations of the injection molding process.

These can be derived from the equation of state of the material which links the pressure, the specific volume, and the temperature. It is therefore also called $p v T$ data [20]. This data is usually provided as pvT diagrams which show the specific volume $v$ as a function of pressure $p$ and the absolute temperature $T$. The commonly used 
model, also used by simulation software, for describing the curves of such a diagram is the 2-domain Tait model which is given as $[2,20]$

$$
v(p, T)=v_{0}(T) \cdot\left[1-C \ln \left(1+\frac{p}{B(T)}\right)\right]+v_{t}(p, T)
$$

where $C=0.0894$ is a constant. The two domains are equal to the solid and molten phase of the material which are separated by the transition temperature $T_{t}$ which is again given as

$$
T_{t}=b_{5}+b_{6} p
$$

In the lower temperature region, i.e. the solid phase with $T<T_{t}$, the missing functions of Equation 4 are given as

$$
\begin{gathered}
v_{0}(T)=b_{1 s}+b_{2 s}\left(T-b_{5}\right), \\
B(T)=b_{3 s} \exp \left[\left(-b_{4 s}\left(T-b_{5}\right)\right],\right. \\
v_{t}(p, T)=b_{7} \exp \left[b_{8}\left(T-b_{5}\right)-b_{9} p\right] .
\end{gathered}
$$

Respectively, the upper temperature region, i.e. the molten phase with $T>T_{t}$, is described by

$$
\begin{gathered}
v_{0}(T)=b_{1 m}+b_{2 m}\left(T-b_{5}\right), \\
B(T)=b_{3 m} \exp \left[\left(-b_{4 m}\left(T-b_{5}\right)\right],\right. \\
v_{t}(p, T)=0 .
\end{gathered}
$$

The unknowns $b_{1 s}, b_{2 s}, b_{3 s}, b_{4 s}, b_{1 m}, b_{2 m}, b_{3 m}, b_{4 m}, b_{5}, b_{6}, b_{7}, b_{8}$, and $b_{9}$ in the

Equations 5-7 are all data-fitted coefficients. 


\section{FEEDSTOCK CHARACTERIZATION}

\subsection{Feedstocks}

Two ceramic powder feedstocks, one commercial and one custom-made, were used and characterized in this work. The key properties of the commercial Catamold ${ }^{\circledast}$ TZP-A supplied by BASF, Ludwigshafen, Germany are shown in Table 1. The feedstock is based on a polyacetal binder, and the debinding happens catalytically by exposing it to a nitric acid atmosphere. As a result, the binder is decomposed in its monomers below its actual melt temperature. The efficient debinding and the good dimensional control are the main advantages claimed by the supplier. The compounds was used, because zirconium dioxide $\left(\mathrm{ZrO}_{2}\right)$ is among the most widely ceramic powders [5].

The custom-made feedstock "GoMikro $\mathrm{ZrO}_{2}$ ", the research equivalent of the Catamold" feedstock, was compounded on-site at the Karlsruhe Institute of Technology (KIT), Eggenstein-Leopoldshafen, Germany. Its key properties are also shown in Table 1. The feedstock is based on a mixture of polyethylene (PE) and wax as the binder system. The debinding happens usually thermally or in a solvent. The major advantage is the easy setup and low investment for debinding. The feedstocks from KIT are actually made for micro powder injection molding and the GoMikro $\mathrm{ZrO}_{2}$ should therefore provide good flow properties. The powder content was 50 vol\% (87 wt\%). The density and powder content were therefore not measured as outlined for the commercial feedstock in the following sections. 
Table 1: Key specifications of the characterized powder feedstocks.

\begin{tabular}{|l|l|l|}
\hline Compound & Catamold ${ }^{\circledR}$ TZP-A & GoMikro ZrO $_{2}$ \\
\hline Type & Ceramic & Ceramic \\
\hline Powder material & Zirconium dioxide & Zirconium dioxide \\
\hline Binder material & polyacetal & PE, wax, and stearic acid \\
\hline Debinding & Catalytically & Thermally, often supported by solvent pre-debinding \\
\hline Processing temperature $/{ }^{\circ} \mathrm{C}$ & $170-180$ & $150-200$ \\
\hline Mold temperature $/{ }^{\circ} \mathrm{C}$ & $138 / 145$ & n.a. \\
(recommended $/$ maximum) & & \\
\hline
\end{tabular}

\subsection{Density}

As samples for the measurement of the density and the thermal properties of the feedstocks circular discs were molded with a thickness of $2 \mathrm{~mm}$ and a diameter of $10 \mathrm{~mm}$. The density of the feedstocks was determined by means of the widespread Archimedes' principle. For each compound, the mass of three samples was determined with a precision scale. The results are listed in Table 2.

Table 2: Determined densities of the used powder feedstocks. Average of three measurement, confidence level: $95 \%$.

\begin{tabular}{|l|l|}
\hline Compound & Density / $\left(\mathrm{g} \mathrm{cm}^{-3}\right)$ \\
\hline Catamold TZP-A & $3.487 \pm 0.009$ \\
\hline GoMikro $\mathrm{ZrO}_{2}$ & $3.494 \pm 0.010$ \\
\hline
\end{tabular}




\subsection{Powder content}

The determination of the powder content is often the first step when characterizing powder feedstocks. The high powder content in the feedstocks heavily affects the rheological, thermal, and mechanical properties of the feedstock and also the quality of the final part. Knowledge about the exact powder content is therefore essential. The powder content was measured for the Catamold ${ }^{\circledR}$ compound in two different ways:

- Method 1: The granules were heated in a debinding furnace (Carbolite HT6/28, resolution: $0.5^{\circ} \mathrm{C}$ ) in air from approximately $23^{\circ} \mathrm{C}$ up to $600{ }^{\circ} \mathrm{C}$ with a heating rate of $2{ }^{\circ} \mathrm{C} / \mathrm{min}$ and again cooled down to room temperature. The total mass of the feedstock was measured before and after the heating with a lab scale (resolution: $1 \mathrm{mg}$ ). The binder burnt during the heating and caused the difference in mass. This method was not applicable to the metal feedstock, because the metal powder oxidized in the air and gained mass.

- Method 2: The granules were heated in a differential scanning calorimetry (DSC) device (Netzsch STA $409 \mathrm{C} / \mathrm{CD}$ ) in nitrogen atmosphere from $25^{\circ} \mathrm{C}$ up to $1000^{\circ} \mathrm{C}$ with a heating rate of $10^{\circ} \mathrm{C} / \mathrm{min}$ and again cooled down to $23^{\circ} \mathrm{C}$. The mass was measured during the entire process by the DSC device.

All heating rates were typical values for the applied devices. Heating up to at least $600^{\circ} \mathrm{C}$ ensured that the binder and all organic additives burnt completely, so that the left over mass could be related to the powder. The powder content by weight $\Phi_{w t}$ was 
actually calculated from the mass measurements, and the powder content by volume $\Phi_{v o l}$ was derived based on the density of the binder and the powder according to

$$
\Phi_{\text {vol }}=\frac{\frac{m_{p}}{\rho_{p}}}{\frac{m_{p}}{\rho_{p}}+\frac{m_{b}}{\rho_{b}}}
$$

where $m_{p}$ and $\rho_{p}$ are the mass and density of the powder, $m_{b}$ and $\rho_{b}$ are the mass and density of the polymer binder. The mass and density of additives was neglected. The density of the powder and binder were taken from the material data sheet and certificate.

The results of the measurements are summarized in Table 3. The measured values are in good agreement to each other with only up to about $1 \%$ deviation and only up to about $2 \%$ higher powder contents than the supplier states (derived from the provided oversizing factor). This discrepancy could be attributed to deviations between the assumed and true density for the binder and powder materials, as the manufacturer did not provide detailed information.

Table 3: Determined powder content of the commercial powder feedstocks.

\begin{tabular}{|l|l|l|}
\hline Reference & \multicolumn{2}{|c|}{ Catamold TZP-A } \\
\hline & content by weight & content by \\
\hline & $\Phi_{w t} / \%$ & volume $\Phi_{v o l} / \%$ \\
\hline Method 1 & 81.7 & 50.8 \\
\hline Method 2 & 81.0 & 49.6 \\
\hline Average & 81.4 & 50.2 \\
\hline Supplier & 79.3 & 46.9 \\
\hline
\end{tabular}




\subsection{Specific heat capacity}

The specific heat capacity (at constant pressure) was measured by means of the high pressure differential scanning calorimeter Netzsch DSC 204 made by NetzschGerätebau, Selb, Germany. The disc sample mass was $55 \mathrm{mg}$ and $58 \mathrm{mg}$ for the GoMikro and Catamold ${ }^{\circledR}$ feedstock, respectively. For every material, three measurement cycles were run in argon atmosphere. The reported value for the specific heat capacity is hence the mean value of all three cycles. Every cycle consisted of a heating phase from $25^{\circ} \mathrm{C}$ to $180^{\circ} \mathrm{C}$ and a cooling phase back to $25^{\circ} \mathrm{C}$ with a heating or respectively cooling rate of $10^{\circ} \mathrm{C} \mathrm{min}^{-1}$ (complies with ASTM E 1269). The heat capacity was determined during the heating phase at temperature steps of $10^{\circ} \mathrm{C}$. The results are shown in Figure

1.

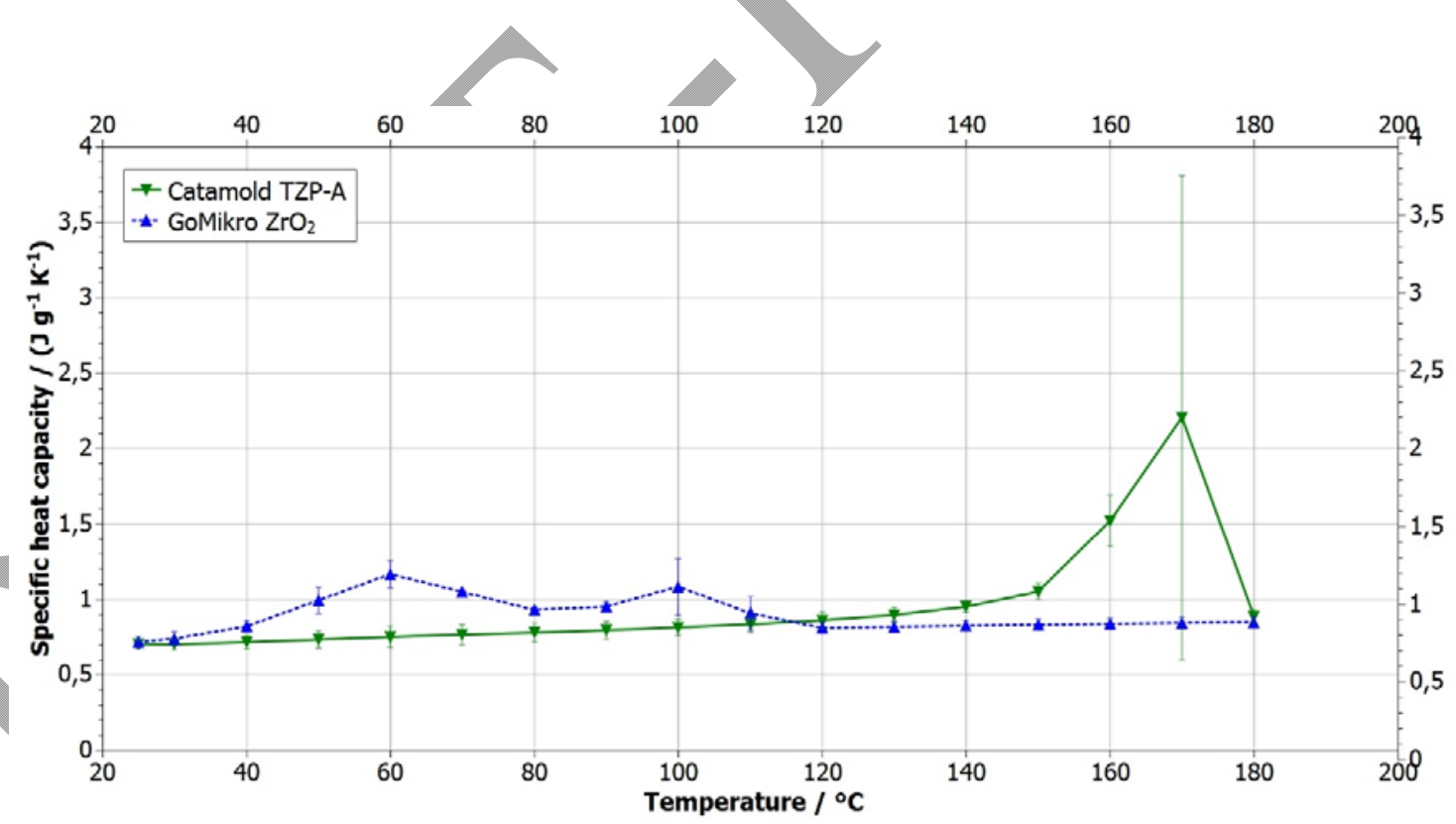

Figure 1: Measured values for the specific heat capacity of the investigated feedstocks and typical values for POM from BASF (from ASMI data base [26]). The measurement was directly done by a DSC analysis. The values are the average of three heating and cooling cycles at a rate of $10^{\circ} \mathrm{C} \mathrm{min}^{-1}$, the error bars represent the standard measurement uncertainty, confidence level: $95 \%$. 
As expected, the heat capacity is a function of temperature. It must also be kept in mind that the heating rate influences the results of heat capacity measurements [27]. The specific heat capacity of the Catamold ${ }^{\circledR}$ compound varies from $0.7 \mathrm{~J} \mathrm{~g}^{-1} \mathrm{~K}^{-1}$ to $2.2 \mathrm{~J} \mathrm{~g}^{-1} \mathrm{~K}^{-1}$, i.e. by a factor three within the investigated temperature range. The heat capacity and the measurement uncertainty show a significant increase in the temperature range of $160^{\circ} \mathrm{C}$ to $180^{\circ} \mathrm{C}$. This correlates to the melting of the crystalline areas in the POM binder at its melting temperature of about $170^{\circ} \mathrm{C}$.

The specific heat capacities of the GoMikro feedstock vary in the range from $0.7 \mathrm{~J} \mathrm{~g}^{-1} \mathrm{~K}^{-1}$ to $1.2 \mathrm{~J} \mathrm{~g}^{-1} \mathrm{~K}^{-1}$, i.e. approximately by a factor two. The compound shows a noticeable, but less pronounced increase in heat capacity and measurement uncertainty, namely at about $60^{\circ} \mathrm{C}$ and at about $100^{\circ} \mathrm{C}$. Likewise, these peaks correlate to the melting temperatures of the wax and the PE in the binder system, respectively. The difference between the commercial and non-commercial compounds are caused by the different binder systems with their varying specific heat capacity and the varying powder load.

The dependency of the heat capacity on the temperature is much less pronounced for the feedstocks compared to plastics. A reference curve for the specific heat capacity of pure POM from BASF is included in Figure 1, where the heat capacity shows a much more volatile behavior and varies from about $1.4 \mathrm{~J} \mathrm{~g}^{-1} \mathrm{~K}^{-1}$ to $10.1 \mathrm{~J} \mathrm{~g}^{-1} \mathrm{~K}^{-1}$, i.e. by a factor of roughly seven. In general, the heat capacity of the feedstocks is much lower compared to pure plastics. 
The investigated compounds exhibit typical values and qualitatively similar variations compared to other powder feedstocks. In literature, values of $0.7 \mathrm{~J} \mathrm{~g}^{-1} \mathrm{~K}^{-1}$ to $0.9 \mathrm{~J} \mathrm{~g}^{-1} \mathrm{~K}^{-1}$ for mullite-zirconia, $0.8 \mathrm{~J} \mathrm{~g}^{-1} \mathrm{~K}^{-1}$ to $1.2 \mathrm{~J} \mathrm{~g}^{-1} \mathrm{~K}^{-1}$ for silicon nitride, $0.9 \mathrm{~J} \mathrm{~g}^{-1} \mathrm{~K}^{-1}$ to $1.5 \mathrm{~J} \mathrm{~g}^{-1} \mathrm{~K}^{-1}$ for aluminum nitride feedstocks are reported [27-31].

\subsection{Measurement of the thermal conductivity}

The thermal conductivity of the feedstocks was determined indirectly by the measurement of the thermal diffusivity in a laser flash analysis. The thermal diffusivity was measured by means of the laser flash apparatus Netzsch LFA 427. In the laser flash analysis, the top surface of the sample was heated up with a short laser flash and the introduced heat spread over the specimen. An infrared sensor monitored the timedependent temperature distribution on the lower surface of the sample from which the thermal diffusivity could be inferred. The instrument operated in accordance to ISO 22007-4 for the determination of the thermal conductivity $[35,36]$.

For each material, the laser flash analysis was conducted with one of the molded disc samples from the density measurements. The temperature range was $25^{\circ} \mathrm{C}$ to $180{ }^{\circ} \mathrm{C}$ with temperature steps of $10^{\circ} \mathrm{C}$. The reported value of the thermal diffusivity is the average of five measurements at every temperature step. 
The thermal conductivity $\lambda$ was derived from the thermal diffusivity $\alpha$ by taking into account the density $\rho$ and the specific heat capacity $c_{p}$ as

$$
\lambda=\alpha \rho c_{p}
$$

According to Equation 9 and the error propagation, the measurement uncertainty $u(\lambda)$ of the thermal conductivity is given by

$$
\frac{u(\lambda)}{\lambda}=\sqrt{\left(\frac{u(\alpha)}{\alpha}\right)^{2}+\left(\frac{u(\rho)}{\rho}\right)^{2}+\left(\frac{u\left(c_{p}\right)}{c_{p}}\right)^{2}}
$$

For the density and the heat capacity, the values from above were used. This is a simplification and introduces most likely a deviation, since the density was measured at room temperature and not for every temperature step in accordance to the heat capacity and temperature conductivity. The results are shown in Figure 2. 


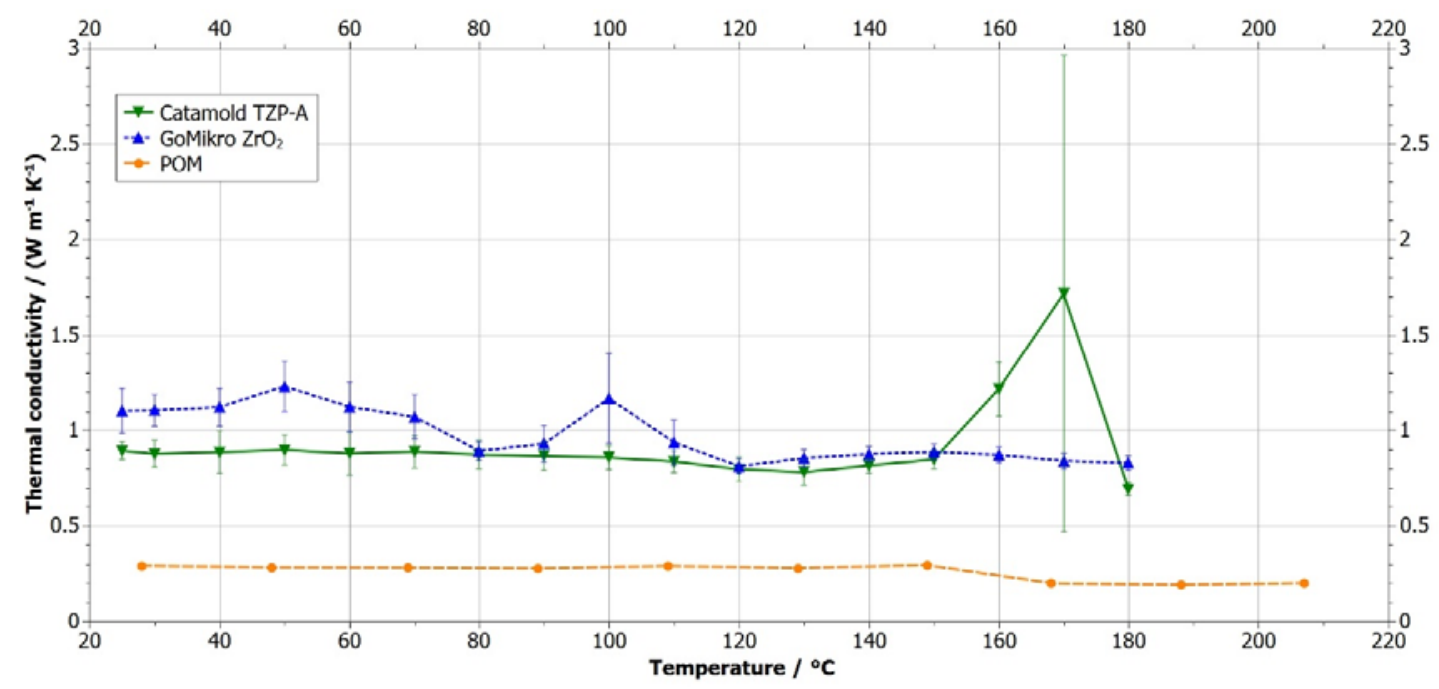

Figure 2: Measured values for the thermal conductivity of the investigated feedstocks and typical values of pure POM from BASF (from ASMI data base [26]). The measurement was indirectly done by measuring the thermal diffusivity with a laser flash analysis. The values are the average of five measurements. The error bars represent the standard measurement uncertainty, confidence level: $95 \%$.

Due to the dependency of the thermal conductivity on the heat capacity, the Catamold ${ }^{\circledR}$ compounds also showed significant peaks from $160^{\circ} \mathrm{C}$ to $180^{\circ} \mathrm{C}$. The large measurement uncertainty was also caused by the heat capacity. The density and thermal diffusivity measurements showed much smaller errors.

Theoretically, the thermal conductivity $\lambda$ of a powder feedstock can be computed by the direct rule of mixtures for powders and binders with comparable conductivities

as $[31,37]$

$$
\lambda=\left(1-\Phi_{v o l}\right) \lambda_{b}+\Phi_{v o l} \lambda_{p}
$$

or accordingly to the inverse rule of mixtures for powders with significantly different conductivities from the binder as $[1,37]$ 


$$
\frac{1}{\lambda}=\frac{\left(1-\Phi_{v o l}\right)}{\lambda_{b}}+\frac{\Phi_{v o l}}{\lambda_{p}}
$$

with the powder volume fraction $\Phi_{v o l}$ and the thermal conductivities $\lambda_{b}$ and $\lambda_{p}$ of the binder and powder, respectively.

The theoretical conductivity of the feedstocks was determined according to Equation 11 as about 1-2 $\mathrm{W} \mathrm{m}^{-1} \mathrm{~K}^{-1}$ ). Except for the characteristic peaks of both materials, the two ceramic feedstocks show very similar thermal conductivity of about $1 \mathrm{~W} \mathrm{~m}^{-1} \mathrm{~K}^{-1}$. Thus, the measured values are in good agreement with the theoretical value. The thermal conductivity of the ceramic feedstocks is hence situated at the lower end of the typical range of zirconium oxide of about 1-3 $\mathrm{W} \mathrm{m}^{-1} \mathrm{~K}^{-1}[38,39]$, but noticeably higher than for the pure binder of typically about $0.3 \mathrm{~W} \mathrm{~m}^{-1} \mathrm{~K}^{-1}[1]$. Discrepancies are also introduced by the measurement uncertainties of density and heat capacity.

\subsection{Measurement of the viscosity}

The viscosity data of the feedstocks was measured using the high pressure capillary rheometer Göttfert Rheograph 25 made by Göttfert Werkstoff-Prüfmaschinen, Buchen,

Germany. The rheometer determined the wall shear rate and wall shear stress based on the measurement of the pressure drop over the capillary and a given flow rate. For every material, the measurement procedure was conducted for three differently long capillaries (diameters of $10 \mathrm{~mm}, 20 \mathrm{~mm}$, and $30 \mathrm{~mm}$ ) and three different temperature levels (low, medium, high) in the recommended processing window of each individual material (Catamold TZP-A: $170,175,180{ }^{\circ} \mathrm{C}$; GoMikro ZrO2: 150, $160,170{ }^{\circ} \mathrm{C}$ ). The 
viscosity was measured at shear rates in the order of approximately $1 \mathrm{~s}^{-1}$ to $10^{4} \mathrm{~s}^{-1}$. The measurement and data processing procedure was established in accordance to ASTM D 3835. Afterwards, the data was processed with Göttfert WinRheo II. The software applied the Weissenberg-Rabinowitsch and Bagley correction to the recorded viscosity data to calculate the true viscosity data by consideration of the different capillary lengths and temperature levels. Finally, the data was fitted to the Cross-WLF viscosity model and the parameters were extracted using Autodesk Simulation Moldflow Insight $2015^{\circledR}$ (ASMI) made by Autodesk, San Rafael, CA, USA and SigmaSoft ${ }^{\circledR}$, developed by SIGMA Engineering, Aachen, Germany.

The results of the viscosity measurements and the subsequent fitting of the viscosity are shown in Figure 3 and Table 4 where they are compared to typical values of the pure POM binder of the Catamold ${ }^{\circledR}$ feedstock. A comparison to the PE/wax binder was not possible due to the complex structure and hence the general unavailability of viscosity data of waxes.

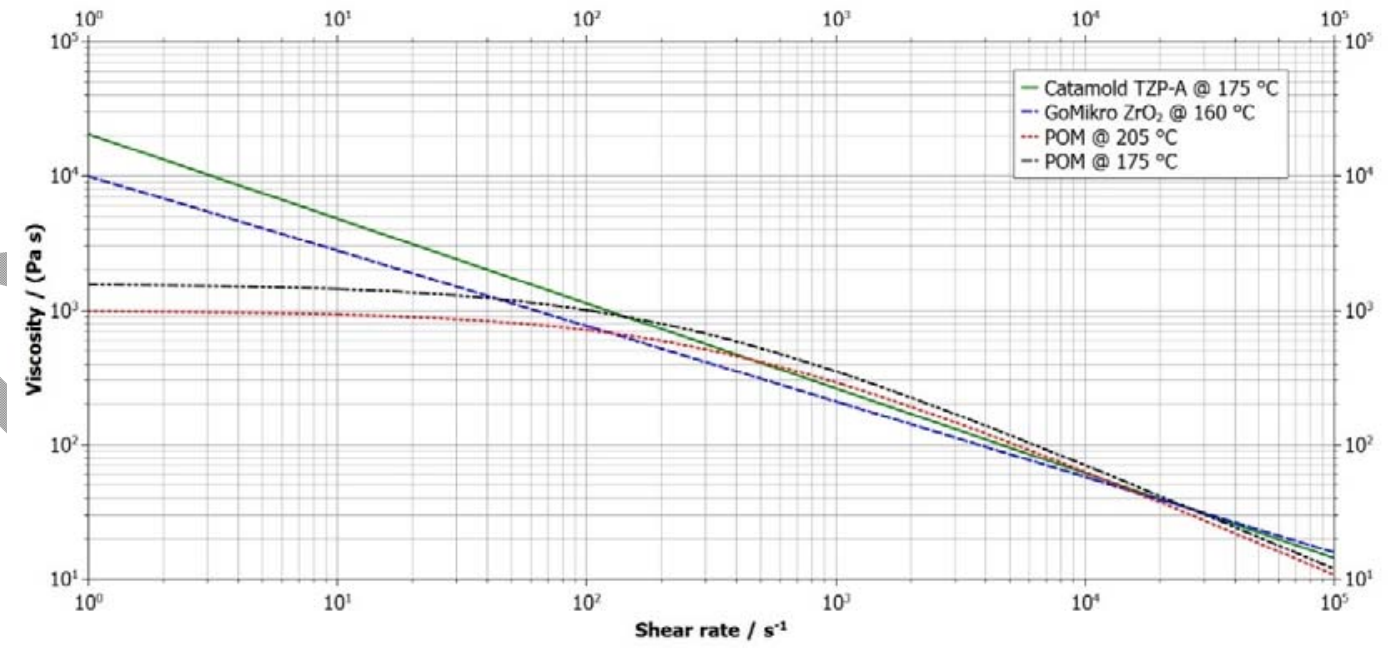

Figure 3: Fitted viscosity curves of the investigated feedstocks at their typical processing temperature and reference curves of POM according to the Cross-WLF model and the parameters from Table 4.10. 
Table 4: Data-fitted parameters for the Cross-WLF model describing the viscosity of the feedstocks and reference values of a pure POM from BASF (from ASMI data base [26]). The values given are partially rounded for easier perception.

\begin{tabular}{|l|l|l|l|l|l|l|l|}
\hline Parameter & $\boldsymbol{n}$ & $\boldsymbol{\tau}^{\boldsymbol{*}}$ & $\boldsymbol{D}_{\mathbf{1}}$ & $\boldsymbol{D}_{\mathbf{2}}$ & $\boldsymbol{D}_{\mathbf{3}}$ & $\boldsymbol{A}_{\mathbf{1}}$ & $\boldsymbol{A}_{\mathbf{2}}$ \\
\hline Unit & 1 & $\mathrm{~Pa}$ & $\mathrm{~Pa} \mathrm{~s}$ & $\mathrm{~K}$ & $\mathrm{~K} \mathrm{~Pa}^{-1}$ & 1 & $\mathrm{~K}$ \\
\hline Catamold TZP-A & 0.3683 & 1305 & $1.70710^{23}$ & 223.15 & 0 & 47.742 & 51.6 \\
\hline POM & 0.212 & 322188 & $1.18010^{12}$ & 223.15 & 0 & 25.13 & 51.6 \\
\hline
\end{tabular}

The curves show that in contrast to plastics, the powder feedstocks do not exhibit a Newtonian plateau at low shear rates - which is a typical behavior for feedstocks. The critical shear stress $\tau^{*}$, i.e. the transition from Newtonian to power-law region, is situated at very low values (maximum of about $1300 \mathrm{~Pa}$ ) compared to POM (about $320000 \mathrm{~Pa}$ ) which illustrates the absence of the Newtonian plateau.

The GoMikro feedstocks shows a lower viscosity than the POM at medium viscosity values and lower than the Catamold ${ }^{\circledR}$ over almost the entire range which proves its applicability for thin walled and micro plastic parts. Besides the characteristic viscosity increase at low shear rates, Catamold ${ }^{\circledR}$ TZP-A exhibits similar viscosity than the pure POM.

According to the presented Cross-WLF model, the term 1- $n$ describes the slope of the viscosity curves in the power-law region, i.e. the sensitivity of the shear thinning to the shear rate. Since the determined power-law index $n$ of the feedstocks is higher than for POM, the feedstocks seem less sensitive to shear thinning. This is true for high shear 
rates $\left(>5000 s^{-1}\right)$ where the power-law region of POM is fully developed. At low shear rates though, the feedstocks show stronger shear thinning tendency, but also much higher absolute viscosity values owing to the missing Newtonian plateau.

\subsection{Measurement of the pvT data}

The $p v T$ data of the feedstocks was also measured using the Göttfert Rheograph 25. The measurements were carried out starting at the maximum individual allowed processing temperature for each feedstock and then sweeping the temperature down to $40{ }^{\circ} \mathrm{C}$ to cover the entire processing and cooling window of the materials. The chosen temperature steps were different for each feedstock in order to have good resolution of the acquired data in the process window and at the transition temperature. At each temperature level, the rheometer applied a force accordingly to the investigated pressure level to the finite material sample. The contraction of the sample with temperature was measured from which the sample volume could be derived.

Before acquiring data at any temperature, the material was allowed to rest and settle to prevent from any influence of possible material relaxation.

The measured data and the fits for all four tested feedstocks are shown in Figure 4. Additionally, it provides also the pvT data of the Catamold ${ }^{\circledR}$ binder POM for comparison. POM shows much higher values for the specific volume because of the missing powder. The main contributor to the increase in specific volume of the feedstocks is the binder. The thermal expansion of the metal and ceramic powders only reaches $<1 \%$ for a temperature difference of $160{ }^{\circ} \mathrm{C}$ (at standard pressure). The increase in specific volume of the feedstocks nonetheless reaches values of more than $12 \%$. 


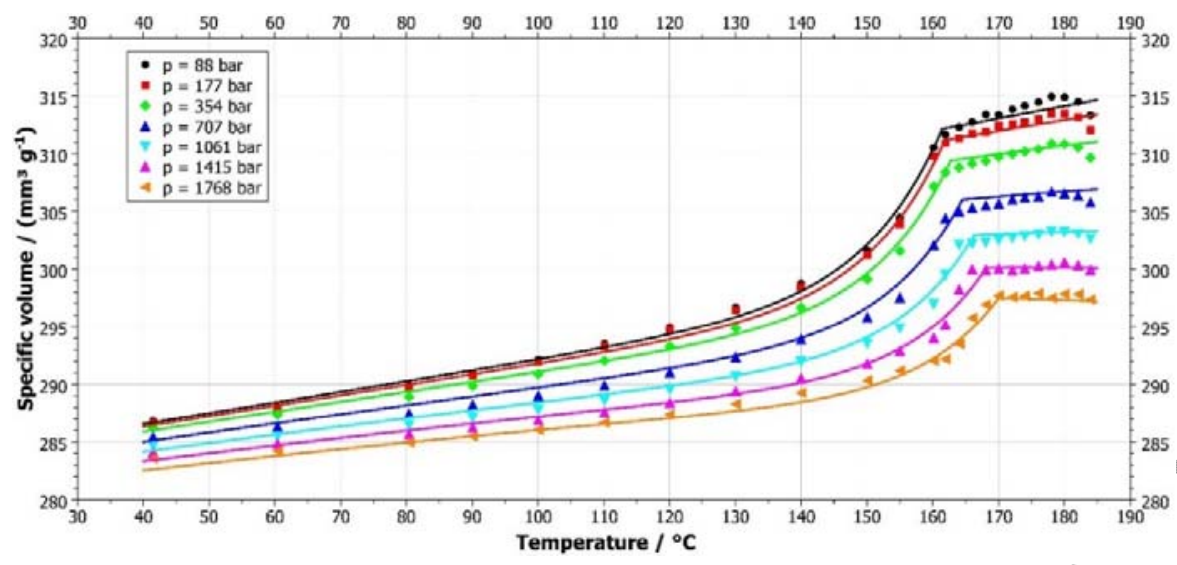

(a) Catamold TZP-A.

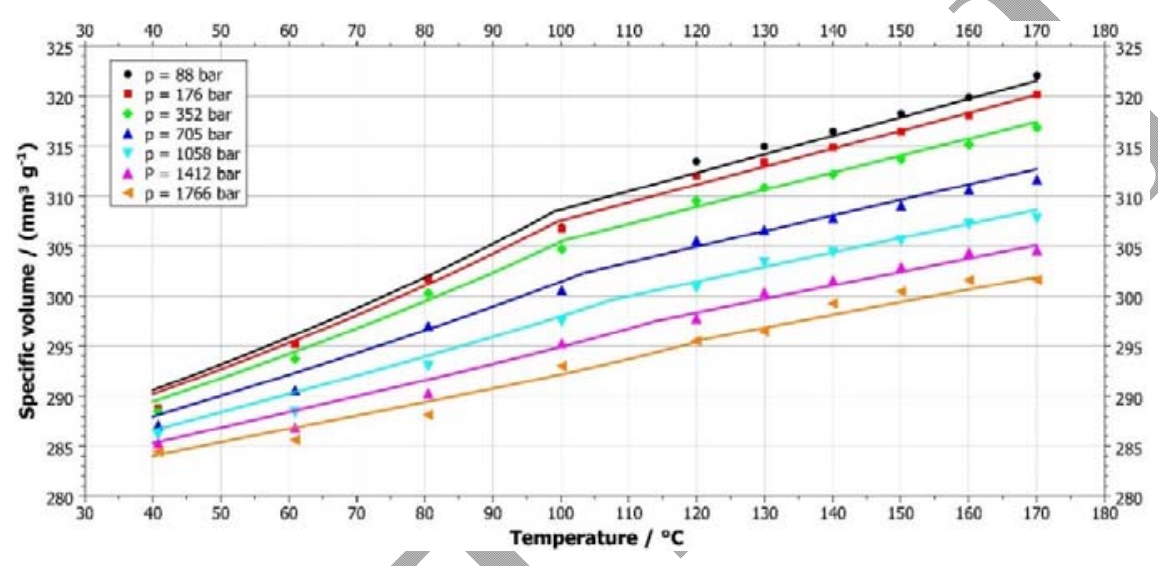

(b) GoMikro ZrO2.

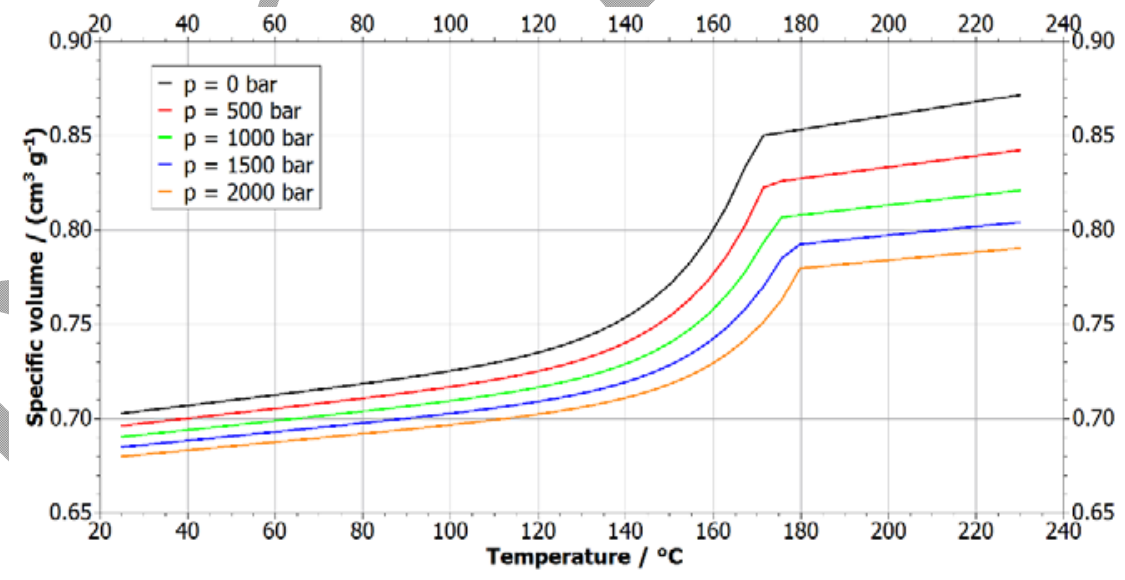

(c) POM N2320 003 BK120 Q600.

Figure 4: Measured pvT data and fitting curves for the two investigated feedstocks and pvT data of POM (Catamold binder) for reference (data taken from ASMI data base [26]). 
The semi-crystalline polyacetal binder is clearly reflected in the pvT curves of the Catamold ${ }^{\circledR}$ feedstock (Figure 4 a) covering the interval of $285 \mathrm{~mm}^{3} \mathrm{~g}^{-1}$ to $315 \mathrm{~mm}^{3} \mathrm{~g}^{-1}$. The data set shows typical curves of a semi-crystalline material, in this case with a very distinct increase in specific volume and a change of the average slope at around $160^{\circ} \mathrm{C}$ to $180^{\circ} \mathrm{C}$. This corresponds to the melt temperature of about $170^{\circ} \mathrm{C}$ (at standard conditions) of the POM binder (compare to the pvT graph of POM), as the melting of the crystalline regions in the material goes along with a significant increase in specific volume.

On the other hand, the GoMikro data sets show neither clear semi-crystalline nor amorphous behavior (Figure 4b). The curves indicate a semi-crystalline behavior with a change in slope at about $110^{\circ} \mathrm{C}$ to $120^{\circ} \mathrm{C}$ which correlates to the melt temperature of the PE part in the binder. However, the transition from the solid to the molten region is indistinct and the semi-crystalline curve can only be sensed in the fit.

Wax typically melts in the temperature range of approximately $40^{\circ} \mathrm{C}$ to $90^{\circ} \mathrm{C}[41]$.

Consequently, it is believed that the wax influences the shape of the curve below the melt temperature of PE and masks the semi-crystalline characteristics. Nonetheless, the exact influence is difficult to estimate, since wax is a very complex material. It would be necessary to collect $p v T$ data with finer temperature resolution to investigate the effect of the wax and to perform a more reliable fitting. 
The corresponding fitting parameters for the measured data for the 2-domain Tait model are listed in Table 5. The determined values of the parameters show good agreement between the fitting by ASMI and SigmaSoft ${ }^{\circledR}$ for the Catamold ${ }^{\circledR}$ feedstock. Deviations are likely caused by the different fitting algorithms of the software. In case of the GoMikro feedstock, comparison with literature values deemed as not meaningful due to the complex recipe of this binder system. Especially the transition phase where the wax is already molten and the PE is still solid causes severe difficulties in creating a reliable Tait diagram. It would be a point of discussion, whether the 2-domain Tait model is suitable and can properly grasp the material behavior. More information about the goodness of fit would have been helpful as at present it can only be derived from the coincidence of measured and simulated data.

Table 5: Data-fitted parameters for the modified 2-domain Tait model describing the pvT data of the investigated Catamold feedstock, determined with ASMI and SigmaSoft ${ }^{\circledR}$, and reference values of a pure POM from BASF (from ASMI data base [26]). The values are shown as generated by the fitting software.

\begin{tabular}{|l|l|l|l|l|}
\hline \multicolumn{2}{|c|}{ Parameter } & \multicolumn{2}{c|}{ Catamold $^{\circledR}$ TZP-A } & POM \\
\hline Name & Unit & ASMI & Sigmasoft & \\
\hline$b_{1 \mathrm{~s}}$ & $10^{-4} \mathrm{~m}^{3} \mathrm{~kg}^{-1}$ & 2.982 & 2.935 & 7.427 \\
\hline$b_{2 \mathrm{~s}}$ & $10^{-8} \mathrm{~m}^{3} \mathrm{~kg}^{-1} \mathrm{~K}^{-1}$ & 9.438 & 9.738 & 27.39 \\
\hline$b_{3 \mathrm{~s}}$ & $10^{8} \mathrm{~Pa}$ & 4.0432 & 3.3399 & 3.21847 \\
\hline$b_{4 \mathrm{~s}}$ & $10^{-3} \mathrm{~K}^{-1}$ & 7.296 & 9.984 & 2.427 \\
\hline$b_{1 \mathrm{~m}}$ & $10^{-4} \mathrm{~m}^{3} \mathrm{~kg}^{-1}$ & 3.131 & 3.131 & 8.496 \\
\hline$b_{2 \mathrm{~m}}$ & $10^{-7} \mathrm{~m}^{3} \mathrm{~kg}^{-1} \mathrm{~K}^{-1}$ & 1.179 & 1.646 & 3.689 \\
\hline$b_{3 \mathrm{~m}}$ & $10^{8} \mathrm{~Pa}^{-3}$ & 2.38286 & 2.19627 & 1.26898 \\
\hline$b_{4 \mathrm{~m}}$ & $10^{-3} \mathrm{~K}^{-1}$ & 9.976 & 7.532 & 2.514 \\
\hline$b_{5}$ & $\mathrm{~K}$ & 434.15 & 435.37 & 443.15 \\
\hline$b_{6}$ & $10^{-8} \mathrm{~K} \mathrm{~Pa}^{-1}$ & 4.9 & 3.3824 & 3.75 \\
\hline$b_{7}$ & $10^{-5} \mathrm{~m}^{3} \mathrm{~kg}^{-1}$ & 1.484 & 1.43 & 10.7 \\
\hline$b_{8}$ & $10^{-2} \mathrm{~K}^{-1}$ & 8.505 & 7.530 & 5.729 \\
\hline$b_{9}$ & $10^{-9} \mathrm{~Pa}^{-1}$ & 7.389 & 4.795 & 5.289 \\
\hline
\end{tabular}




\section{INJECTION MOLDING EXPERIMENTS}

\subsection{Geometry}

The geometry being used for the validation of the powder injection molding simulations was a double spiral test geometry. The double spiral is depicted in Figure 5. It consisted of the actual spirals and a feed system with a sprue and a sprue gate, i.e. without a runner. The flow entered the cavity directly from the sprue. It was moreover equipped with a sprue puller. The two incorporated spirals were symmetrical. In terms of geometry, they were based on an arithmetic spiral. The cross-section of the spiral tube had a nominal thickness of $1.0 \mathrm{~mm}$ and a nominal width of $2.6 \mathrm{~mm}$. The maximum flow length was about $100 \mathrm{~mm}$ at the center of the flow path.

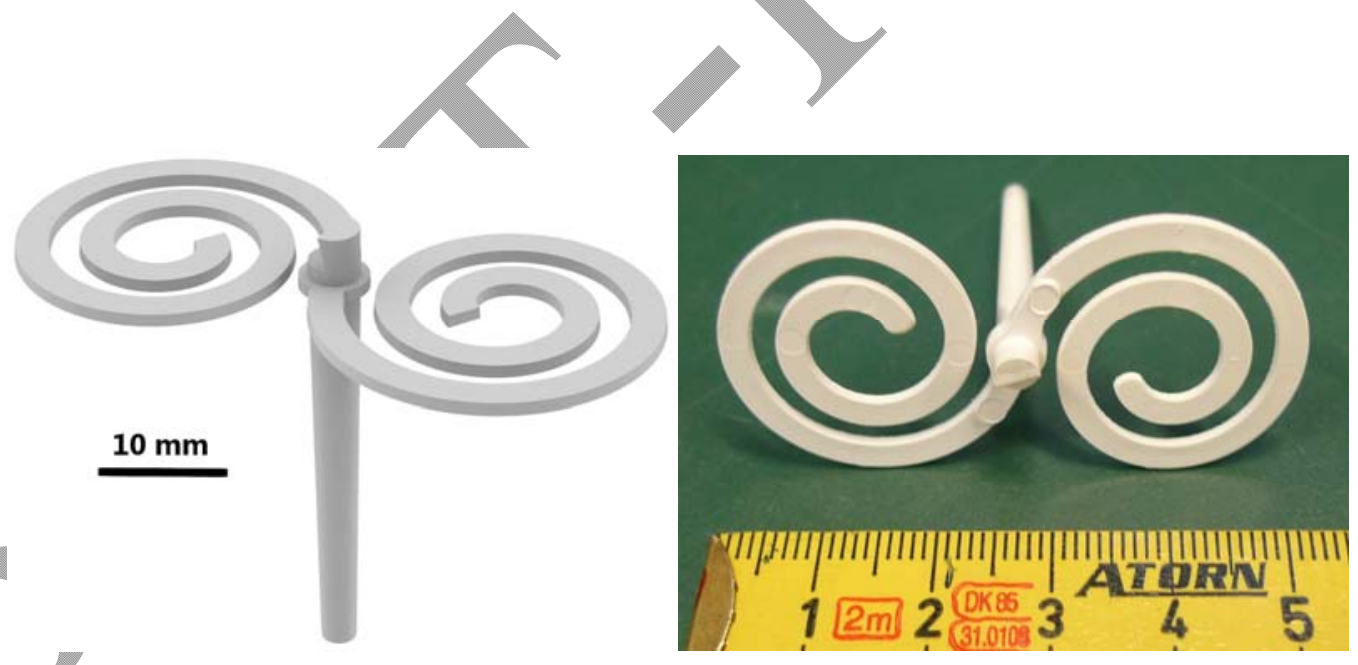
(a) CAD model.
(b) Real spiral.

Figure 5: CAD model and real part of the test spiral being used for the powder injection molding simulations and experiments. 
The flow spiral could be classified as micro precision part, because of the tight tolerances in the micrometer range. The part was selected because of the advanced mold with a sensor array (described in the next section) allowing for in-process monitoring and characterization. The scientific value was the extensive data acquisition which laid the foundation for the performance assessment of the powder feedstocks regarding micro parts and for the process simulations of the injection molding process.

\subsection{Tool}

The used two-plate steel mold was made of 1.2767 (X45NiCrMo16) tool steel and was meant for flow length testing purposes. The mold provided three pressure and three temperature sensors along the flow path of the two separate spiral cavities. The pressure sensors were integrated in one spiral, the temperature sensors in the other. Their exact position and the layout of the cavity as well as the stationary half of the steel mold with the integrated sensors can be seen in Figure 6 . 


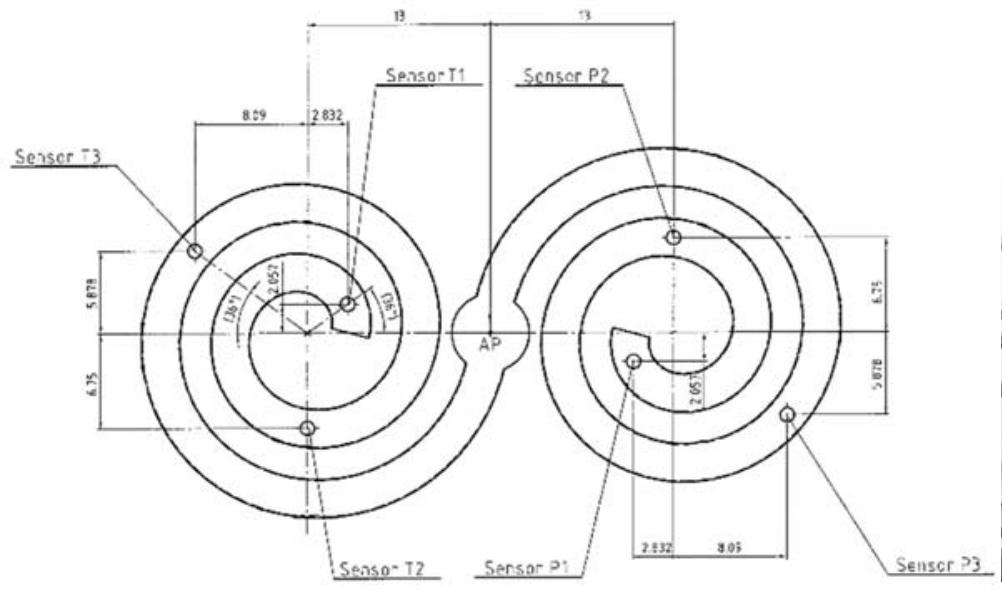

(a) Schematic with sensor positions.

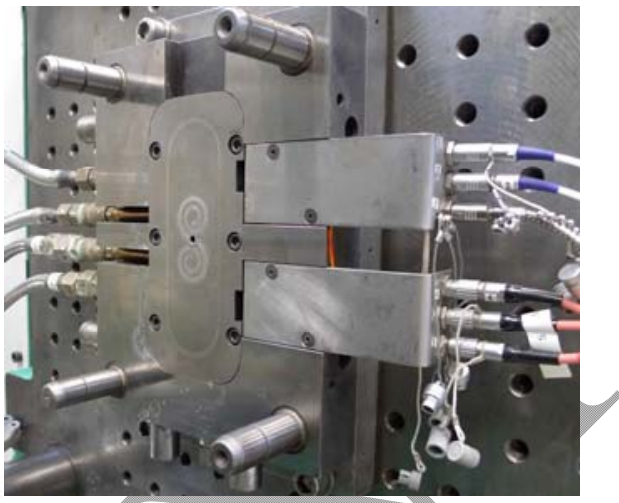

(b) Stationary half.

Figure 6: Drawing of the cavity layout of the double spiral with the positions of the temperature and pressure sensors (denoted with $\mathrm{T}$ and $\mathrm{p}$, respectively) and picture of the stationary half of the double spiral test mold with pressure and temperature sensors (not visible) and their connections (cables on the right) used for the powder injection molding experiments.

The sensor array allowed to investigate the pressure and temperature evolution in the cavity live during the filling phase of the injection molding process. The pressure sensors were of type $6003 \mathrm{~B}$ and the temperature sensors of type 4008B (type $\mathrm{N}$ thermocouple) made by Priamus System Technologies, Schaffhausen, Switzerland. The sensors were exposed to the melt on a diameter of $2.5 \mathrm{~mm}$ and $1.0 \mathrm{~mm}$, respectively. The sampling frequency of the sensors was $200 \mathrm{~Hz}$. The signals of the pressure sensors are denoted in the following sections as $p 1, p 2$, and $p 3$; the temperature sensors were not used in this investigation. In addition to the sensors, the injection molding machine also monitored the applied injection pressure of the hydraulic drive which is denoted as $\mathrm{pM}$ in the following. 


\subsection{Experimental conditions}

Full shots of the double spiral were molded with all four presented feedstocks. The goal was to investigate the pressure development in the cavity as well as to evaluate the flow length and thus the applicability of the feedstocks to micro structures. The flow length was evaluated by an angular measurement of the spirals from which the spiral length could be calculated. The process settings were chosen accordingly to the molded material and are listed in Table 6. The used injection molding machine was an Arburg Allrounder 420 C 600-100 with a screw and nozzle diameter of $15 \mathrm{~mm}$ and $2.0 \mathrm{~mm}$, respectively, and made by Arburg, Loßburg, Germany. The experiments were carried out at the Karlsruhe Institute of Technology (KIT), Eggenstein-Leopoldshafen, Germany. The melt and mold temperatures of the feedstocks were chosen as high as allowed to achieve the best filling and largest flow length.

Table 6: Process settings for the molding of the double spiral geometry with the characterized feedstocks.

\begin{tabular}{|l|l|l|}
\hline Parameter & Catamold ${ }^{\circledR}$ TZP-A & GoMikro ZrO ${ }_{2}$ \\
\hline Nozzle temperature $/{ }^{\circ} \mathrm{C}$ & 180 & 200 \\
\hline Barrel temperature $/{ }^{\circ} \mathrm{C}$ & $172-180$ & $178-200$ \\
\hline Mold temperature $/{ }^{\circ} \mathrm{C}$ & 145 & 51 \\
\hline Injection speed $/ \mathrm{mm} / \mathrm{s}$ & 35 & 40 \\
\hline Packing time $/ \mathrm{s}$ & 2.7 & 2.7 \\
\hline Cooling time $/ \mathrm{s}$ & 35 & 35 \\
\hline
\end{tabular}




\subsection{Experimental results}

The injection time and pressure of the full shots are listed in Table 7. First, it can be noticed that the necessary injection pressures to mold the parts were very high for both feedstocks-exceeding for three materials in fact the nominal maximum injection pressure of the machine of $250 \mathrm{MPa}$.

Table 7: Experimental results for the full shots of the molded test spirals. Reported pressure is the

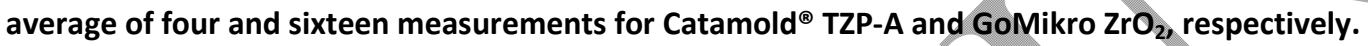
Confidence level: $90 \%$.

\begin{tabular}{|l|l|l|l|}
\hline Compound & Fill time / s & Fill pressure / MPa & Flow length / mm \\
\hline Catamold $^{\circledR} \mathrm{TZP}-\mathrm{A}$ & 0.45 & $262.5 \pm 3.6$ & 95 \\
\hline${\text { GoMikro } \mathrm{ZrO}_{2}}^{0.42}$ & $263.3 \pm 1.2$ & 100 \\
\hline
\end{tabular}

The resulting samples of the full shots of the double test spiral are shown in Figure 7.

The GoMikro feedstock is actually compounded especially for easy flow and the molding of thin-walled and micro parts. This property was indicated by the complete filling of the cavity, whereas the Catamold ${ }^{\circledR}$ feedstock led to short shots; demonstrating that micro injection molding with the Catamold ${ }^{\circledR}$ feedstock can therefore be evaluated as challenging and very dependent on the aspect ratio and flow length of the molded part. 

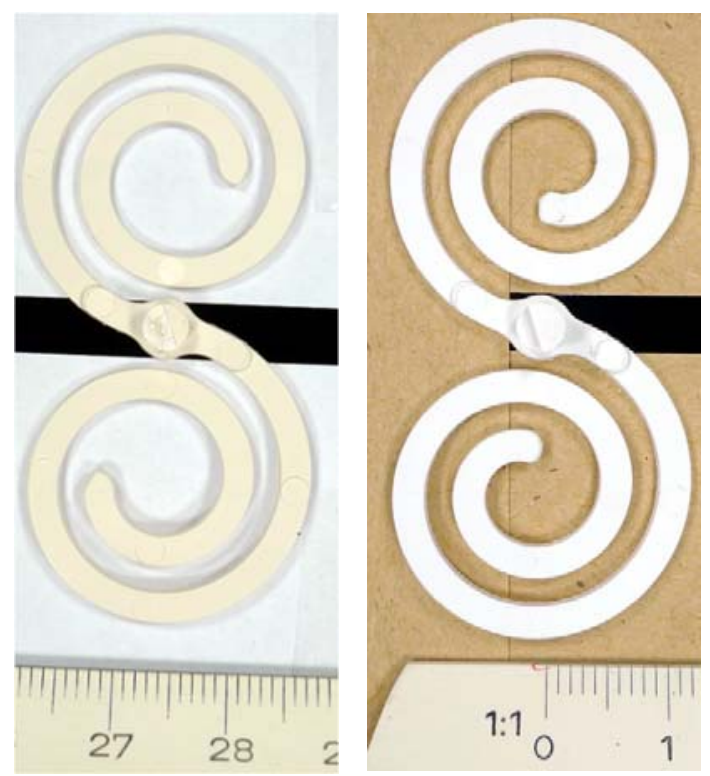

Figure 7: Comparison of the molded spirals for all four used feedstocks. Shown scale in $\mathrm{cm}$. Left: Catamold ${ }^{\circledR}$ TZP-A. Right: GoMikro $\mathrm{ZrO}_{2}$.

\section{INJECTION MOLDING SIMUKATIONS}

\subsection{Simulation set up}

The part was modeled together with the feed system in ASMI. The objective of the simulations was the investigation of the predicted fill time and fill pressure. The simulation outcome was supposed to be compared to the experimental data, in particular the pressure curves of the machine and the sensors in the mold.

The meshed double spiral is shown in Figure 8. The mesh settings are summarized In

Table 8. The mesh density of the side walls of the spirals was adjusted to $150 \mu \mathrm{m}$ to reach about ten elements through the thickness. The value was chosen larger than one tenth of the thickness of the spiral tube of $1.0 \mathrm{~mm}$, but the meshing yielded smaller side length for the elements than the set value. 


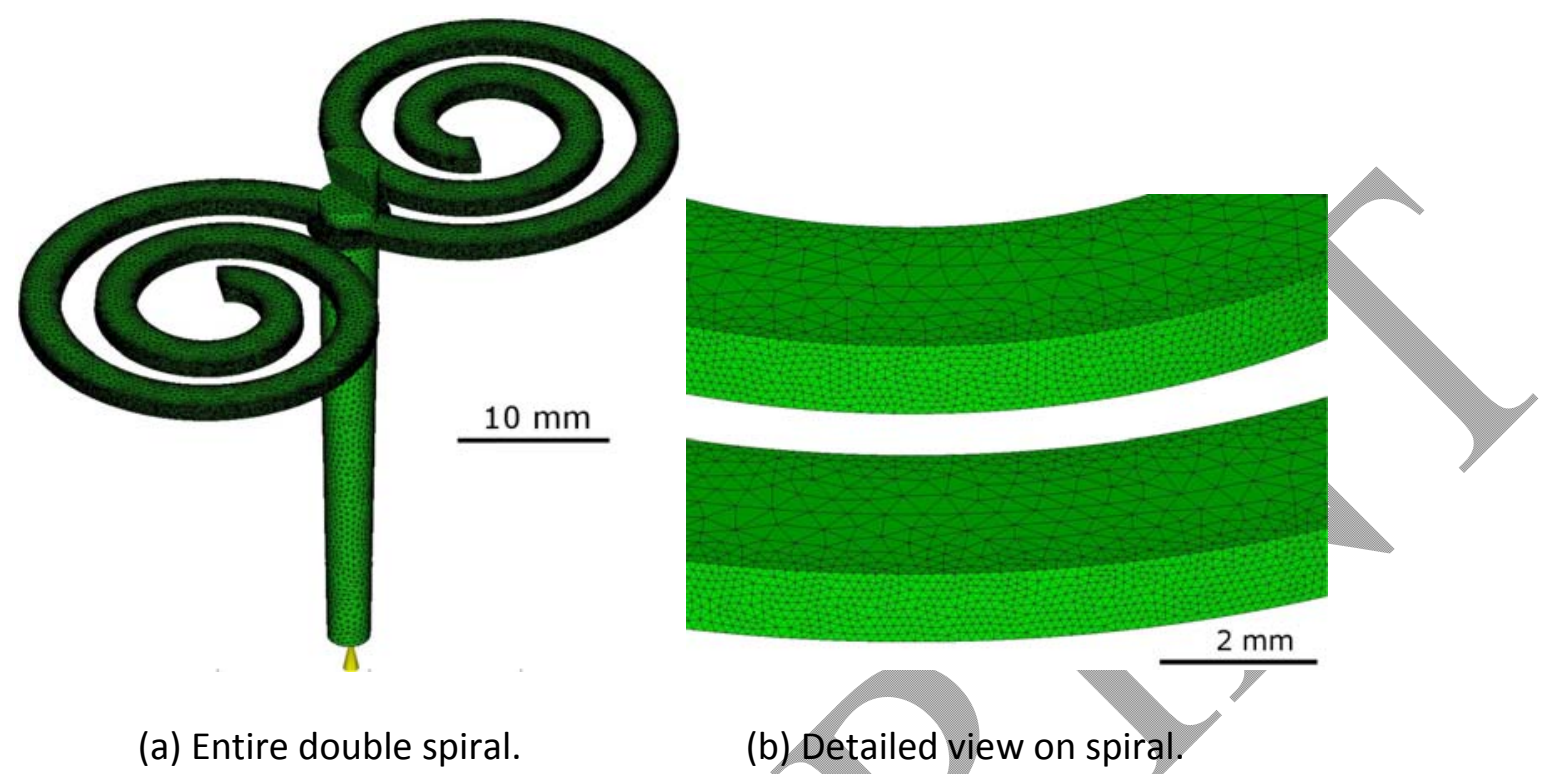

Figure 8: Meshed double spiral with sprue and defined injection location, captured in ASMI.

Table 8: Meshing settings of the double spiral together with the feed system.

\begin{tabular}{|l|l|}
\hline Parameter & Value \\
\hline Specific element edge length at side walls / $\mu \mathrm{m}$ & 150 \\
\hline Global edge length / $\mu \mathrm{m}$ & 500 \\
\hline Minimum number of elements through thickness & 10 \\
\hline Total number of elements & 930000 \\
\hline
\end{tabular}

The processing settings in ASMI 2015 like melt and mold temperature, the material for the virtual mold, as well as the machine were chosen in accordance to the experiments.

The injection location size was chosen as $2.0 \mathrm{~mm}$ in accordance to the size of the nozzle of the injection molding machine. The simulations were run with Catamold ${ }^{\circledR}$ TZP-A. In addition, the injection speed of the screw was monitored by the machine and was introduced to ASMI. The implemented and approximated speed profile is shown in 
Figure 9. In contrast to a constant speed setting, the true speed profile accounted for the finite acceleration and the response time of about $60 \mathrm{~ms}$ of the injection molding machine. The controller first ramped up the screw speed and then tried to adjust it to the nominal value before the speed dropped again at the end of injection. For the comparison to the experiments, the pressure at the injection location and the pressure at four nodes at the same location as the sensors in the real mold were determined.

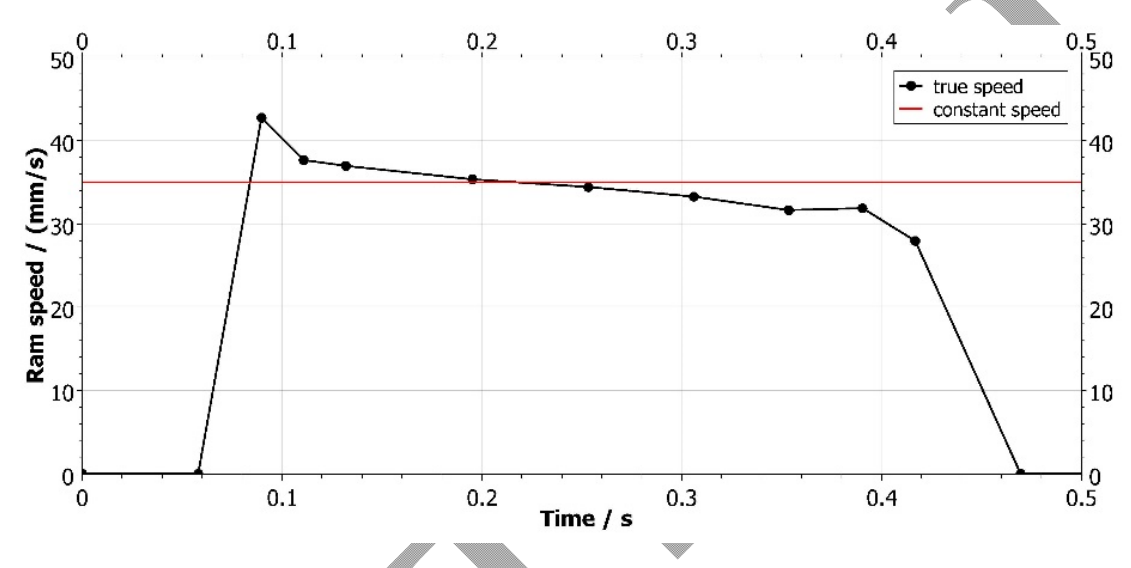

Figure 9: Comparison of a constant speed setting and the true speed profile used for the simulation of the double spiral in ASMI. The curves are exemplary shown for Catamold ${ }^{\circledR}$ TZP-A.

\subsection{Simulation Validation}

The successful application of the established material model can be first reported. All

simulations showed complete filling of the spiral. The results of the simulations and the experiments are shown in Table 9 and Figure 10. In general, the simulations underestimated the injection pressure and fill time levels and gave a discrepancy between all pressure signals. The maximum pressure was predicted as $150 \mathrm{MPa}$ by the simulation in contrast to about $260 \mathrm{MPa}$ in the experiments. The pressure level "p3 sim" reached about $130 \mathrm{MPa}$, whereas the corresponding "p3 exp" reached $50 \mathrm{MPa}$. The 
experimental signals "p2 exp" and "p1 exp" remained at zero, since the flow length was too short to reach the sensors. The simulation on the other hand gave values of about $200 \mathrm{MPa}$ for all three sensor positions. The standard deviation of the measured signals were up to $3 \mathrm{MPa}$ during the rise of the signal when reaching approximately $20 \mathrm{MPa}$ and about $1 \mathrm{MPa}$ at the pressure peak.

Table 9: Predicted process results of the simulations and experimental results from above for comparison.

\begin{tabular}{|l|l|l|l|l|}
\hline Feedstock & Type & Fill time / s & Fill pressure / MPa & Flow length / mm \\
\hline Catamold $^{\circledR}$ TZP-A & Experimental & 0.45 & 263 & 95 \\
& Simulation & 0.23 & 150 & 100 \\
\hline
\end{tabular}

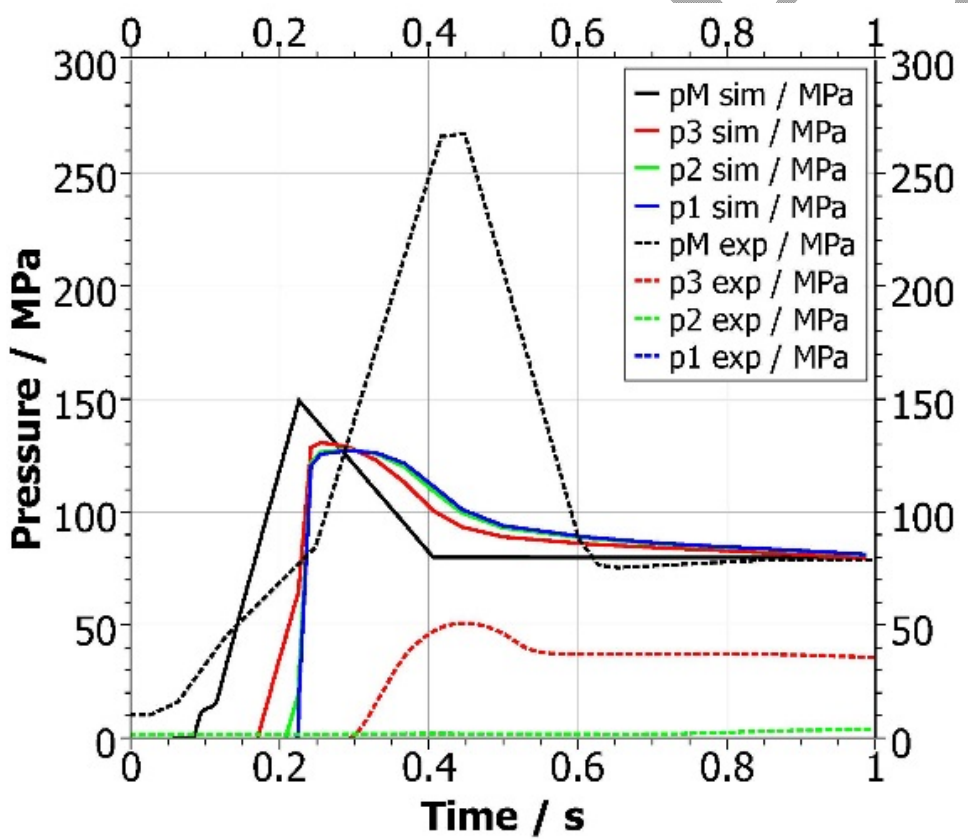

Figure 10: Injection pressure over time of the experiments and simulations with the Catamold ${ }^{\circledR}$ TZP-A feedstocks. The plot contains the pressure signals from the pressure sensors (p1, p2, p3) and the machine (pM). 
The material data base was excellent and up-to-date because of the conducted characterization. Furthermore, the spiral was not a micro part, so that deviations due to software limitations regarding insufficiently implemented microscale effects could be most likely ruled out.

Possible reasons causing the discrepancies are the influence of the particle size and particle shape as well as the feedstock behavior which seemed to be not very well described by the Cross-WLF model - despite the viscosity curves' similarity to power-law curves. The introduction of the Herschel-Bulkley extension to the Cross-WLF model is recommended by some researchers $[8,18]$.

The influence of the viscosity model could be investigated in future work by incorporating the Herschel-Bulkley extension in the simulation. The applicability of current commercial simulation tools employing the regular Cross-WLF model could be evaluated as limited, but showing great potential for polymer resins containing no or less fillers. Furthermore, the material model could be improved by additional, though time-consuming, measurements with a disc rheometer to cover also the viscosity at very low shear rates, where the applicability of the capillary rheometer is limited. 


\section{SUMMARY AND CONCLUSION}

This work comprises a broad and comprehensive material characterization of ceramic powder feedstocks. The aim was to establish material data which can be used fo creating a material model for the simulation of the powder injection molding process and to exemplarily describe the necessary material data.

The powder load of the Catamold ${ }^{\circledR}$ feedstock was determined as 81 wt\% (50 vol\%). The specific heat capacity was measured by DSC with special attention to the temperature dependency. The results of the two compounds were in the typical range for powder feedstocks with distinct peaks attributed to the melting temperatures of the binder components and in general lower than the heat capacity of the pure binder.

The thermal conductivity was measured indirectly by the determination of the thermal diffusivity in a laser flash analysis. The thermal conductivity also showed significant peaks and an increase in measurement uncertainty around the melting temperatures of the binder components which was caused by the contribution of the heat capacity.

Compared to the pure plastic binder, it was found that the feedstocks show as expected a greater thermal conductivity. The lower heat capacity and higher thermal conductivity can both be an issue during the filling phase. The heat carried by the feedstock is less than for plastics and in addition released more quickly. Both effects lead to an increased risk of premature solidification and short shots as well as larger pressure drops. 
The viscosity was successfully measured by means of a capillary rheometer and fitted by the Cross-WLF model for all feedstocks. The curves showed the typical behavior of feedstocks with a missing Newtonian plateau. Literature discusses the necessity of extended viscosity models like Herschel-Bulkley to fully describe this behavior of feedstocks. Regarding the model, the viscosity measurements could be subject of future investigations. The resolution in shear rate should be significantly increased to identify a possible Newtonian plateau. If the Newtonian plateau was absent or covered a small negligible range, the viscosity might still be properly modeled by the Cross-WLF approach. This would facilitate the applicability of existent simulation tools to powder injection molding.

The collected $p v T$ data of the Catamold ${ }^{\circledR}$ feedstock reflected clearly their semicrystalline polyacetal binder with a significant change in specific volume at the melting temperature. The data was successfully fitted by the 2-domain Tait model. In contrast, the curves of the non-commercial GoMikro feedstock resembled neither the typical shape of semi-crystalline nor amorphous materials. The curves were influenced by the different melting points of the two binder components, PE and wax.

In conclusion, collecting and processing material data turned out as an extensive and time-consuming, but vital task for conducting injection molding simulations. Material data base files might not be available or outdated, especially in case of powder 
feedstocks. The necessary material properties for establishing a material data base file were outlined and covered by the performed detailed characterization of two ceramic feedstocks. The material characterization finally enabled to create material data files for the process simulations.

The investigations on powder injection molding commenced with the presentation of the study part: a double spiral test geometry in the millimeter range. The mold of the double spiral was equipped with pressure and temperature sensors enabling the monitoring of the pressure and temperature inside the cavity live during injection. A full shot study was performed to investigate the molding and as basis for comparison to the later conducted simulations. The experiments yielded full shots of the non-commercial feedstock from KIT and short shots of the commercial feedstock from BASF. All tested feedstocks caused very high injection pressures near the machine's nominal maximum pressure. The KIT feedstock could be evaluated as presumably suitable for micro parts. Micro molding with the Catamold ${ }^{\circledR}$ feedstocks on the other hand is expected to be challenging because of the high viscosity and short flow length.

The simulations with Catamold ${ }^{\circledR}$ of the double spiral comprised the part and were compared to the experiments. The speed profile monitored during the molding was introduced to the simulations to gain better results in comparison to a simple constant speed profile. Furthermore, the investigation of the injection pressure measured by the machine and by the sensors revealed that the simulations underestimated both the 
pressure levels and fill times for the Catamold ${ }^{\circledR}$ feedstock. This was also related to the incorrect prediction of a full shot. The main reason for the reported discrepancies was most likely the inadequate viscosity model, i.e. the regular Cross-WLF model. The simulation of powder injection molding had therefore to be evaluated as critical and not entirely reliable with the used ASMI software. However, adapted viscosity models and access to the core of the software provide the potential for enhancements and are recommended as scope of future work. For example, the influence of the viscosity model could be investigated by incorporating the Herschel-Bulkley extension in the simulation.

\section{ACKNOWLEDGMENTS}

This paper reports work undertaken in a collaboration between the Technical University of Denmark (DTU), Kongens Lyngby, Denmark and the Karlsruhe Institute of Technology (KIT), Eggenstein-Leopoldshafen, Germany. The financial and personnel aid of both facilities is greatly acknowledged. Furthermore, the work and collaboration was supported by the Karlsruhe Nano Micro Facilities (KNMF, www.knmf.kit.edu), the Helmholtz Research Infrastructure at Karlsruhe Institute of Technology,(proposal ID: 2014-012-004392) which is also gratefully acknowledged and which made this research possible. 


\section{REFERENCES}

[1] Heaney, D. F., 2012, Handbook of Metal Injection Molding, Woodhead Publishing, Cambridge, UK.

[2] Wang, J., 2012, Some critical issues for injection molding, InTech, Rijeka, Croatia.

[3] Attia, U. M., and Alcock, J. R., 2011, "A review of micro-powder injection moulding as a microfabrication technique," J. Micromechanics Microengineering, 21(4), p. 043001.

[4] Attia, U. M., and Alcock, J. R., 2012, "Fabrication of ceramic micro-scale hollow components by micro-powder injection moulding," J. Eur. Ceram. Soc., 32(6), pp. 11991204.

[5] Piotter, V., 2011, "A review of the current status of MicroPIM," Powder Inject. Molding Int., 5(3), pp. 27-42.

[6] Löhe, D., and Haußelt, J., 2005, Microengineering of Metals and Ceramics. Part I: Design, Tooling and Injection Molding, Wiley-VCH Verlag, Weinheim, Germany.

[7] Urval, R., Lee, S., Atre, S. V., Park, S. J., and German, R. M., 2008, "Optimisation of process conditions in powder injection moulding of microsystem components using a robust design method: part I. primary design parameters," Powder Metall., 51(2), pp. 133-142.

[8] Thornagel, M., 2012, "Injection moulding simulation: New developments offer rewards for the PIM industry," Powder Inject. Molding Int., 6(1), pp. 65-68.

[9] SIGMA Engineering, 2013, "3D moulding simulation - The 'whole process' approach," Met. Powder Rep., 68(3), pp. 30-32.

[10] Costa, F. S., Tosello, G., and Whiteside, B. R., 2009, "Best practice strategies for validation of micro moulding process simulation," Proceedings of the Polymer Process Engineering 2009 Conference, University of Bradford, pp. 331-364.

[11] Vietri, U., Sorrentino, A., Speranza, V., and Pantani, R., 2011, "Improving the predictions of injection molding simulation software," Polym. Eng. Sci., 51(12), pp. 2542-2551.

[12] Khalilian, S. A., Park, S. S., and Freiheit, T. I., 2013, "The Application of Commercial Injection Molding Software to Micro-Component Design and Process Development," Proceedings of the 8th Internation Conference on Micro Manufacturing (ICOMM 2013), pp. 50-56.

[13] Marhöfer, D. M., Tosello, G., Hansen, H. N., and Islam, A., 2013, "Advancements on the Simulation of the Micro Injection Moulding Process," Proceedings of the 10th International Conference on Multi-Material Micro Manufacture (4M), Research Publishing Services, San Sebastian, Spain, pp. 77-81.

[14] Tosello, G., Gava, A., Hansen, H. N., Reinecke, H., Lucchetta, G., and Schoth, A., 2009, "Experimental validation of micro molding simulations using different process setting conditions," Proceedings of the 67th Annual Technical Conference of the Society of Plastics Engineers 2009 (ANTEC 2009), Society of Plastics Engineers (SPE), Chigago, IL, USA, pp. 1787-1793.

[15] Nguyen-Chung, T., Loser, C., Jüttner, G., Pham, T., Obadal, M., and Gehde, M., 2011, "Simulation of the micro-injection moulding process: effect of the thermo- 
rheological status on the morphology," Proc. Inst. Mech. Eng. Part E J. Process Mech. Eng., 225(4), pp. 224-238.

[16] Chen, L., Kietzmann, C., Astbury, D., and Shao, L., 2014, "Advanced cooling simulation technologies for the injection molding process," p. 8.

[17] Islam, A., Giannekas, N., Marhöfer, D. M., Tosello, G., and Hansen, H. N., 2016, "Experimental investigation of comparative process capabilities of metal and ceramic injection moulding for precision applications," J. Micro Nano-Manufacturing, 4(September), p. 031003.

[18] Drummer, D., and Messingschlager, S., 2014, "Ceramic injection molding material analysis, modeling and injection molding simulation," Proceedings of the 29th International Conference of the Polymer Processing Society (PPS-29), AIP Publishing, pp. 582-586.

[19] Yunn, H. S., Muhamad, N., and Sulong, A. B., 2011, "Micro Powder Injection Molding ( $\mu \mathrm{PIM})$ : Review," Appl. Mech. Mater., 52-54, pp.91-96.

[20] Kennedy, P., and Zheng, R., 2013, Flow Analysis of Injection Molds, Carl Hanser Verlag, Munich.

[21] Osswald, T. A., and Rudolph, N., 2014, Polymer Rheology, Carl Hánser Verlag, Munich.

[22] Schramm, G., 1994, A Practical Approach to Rheology and Rheometry, Gebrueder HAAKE, Karlsruhe, Germany.

[23] Reher, E.-O., 2000, "Zur Rheologie von Polymerschmelzen," Sitzungsberichte der Leibniz-Sozietät, 43, pp. 5-23.

[24] Dealy, J. M., and Wang, J., 2013, Melt Rheology and its Applications in the Plastics Industry, Springer Science+Business Media, Dordrecht, The Netherlands.

[25] Göttfert, A., Reher, E.-O., and Balagula, I. M., 2000, "Kapillarrheometer für die Kunststoffverarbeitung. Simulation rheologischer Prozesse," KGK Kautschuk Gummi Kunststoffe, 53(9), pp. 512-517.

[26] Autodesk, 2015, "Autodesk Simulation Moldflow Insight ${ }^{\circledR} . "$

[27] Kowalski, L., and Duszczyk, J., 1999, "Specific heat of metal powder-polymer feedstock for powder injection molding," J. Mater. Sci. Lett., 18, pp. 1417-1420.

[28] Kate, K. H., Onbattuvelli, V. P., Enneti, R. K., Lee, S. W., Park, S. J., and Atre, S. V., 2012, "Measurements of Powder-Polymer Mixture Properties and Their Use in Powder Injection Molding Simulations for Aluminum Nitride," JOM (The J. Miner. Met. Mater. Soc., 64(9), pp. 1048-1058.

[29] Martin, R., Vick, M., Kelly, M., de Souza, J. P., Enneti, R. K., and Atre, S. V., 2013, "Powder injection molding of a mullite-zirconia composite," J. Mater. Res. Technol., 2(3), pp. 263-268.

[30] Lenz, J., Enneti, R. K., Onbattuvelli, V. P., Kate, K. H., Martin, R., and Atre, S. V., 2012, "Powder Injection Molding of Ceramic Engine Components for Transportation," JOM (The J. Miner. Met. Mater. Soc., 64(3), pp. 388-392.

[31] Kate, K. H., Enneti, R. K., Onbattuvelli, V. P., and Atre, S. V., 2013, "Feedstock properties and injection molding simulations of bimodal mixtures of nanoscale and microscale aluminum nitride," Ceram. Int., 39(6), pp. 6887-6897. 
[32] AMETEK Specialty Metal Products, "17-4 PH: The Workhorse of PrecipitationHardening Stainless Steels."

[33] Maxon Motor, 2010, "Innovative CIM / MIM Komponenten," p. 5.

[34] Deutsche Edelstahlwerke, 2015, "Acidur 4542 - Werkstoffdatenblatt X5CrNiCuNb16-4 1.4542," p. 6.

[35] International Organization for Standardization, 2008, "ISO 22007-2:2008

Plastics - Determination of thermal conductivity and thermal diffusivity - Part 2:

Transient plane heat source (hot disc) method."

[36] Netzsch-Gerätebau, 2013, "Laser Flash Analysis -- LFA (LFA427)."

[37] Lobo, H., and Cohen, C., 1990, "Measurement of thermal conductivity of polymer melts by the line-source method," Polym. Eng. Sci., 30(2), pp. 65-70.

[38] Roos, E., and Maile, K., 2008, Werkstoffkunde für Ingenieure - Grundlagen, Anwendung, Prüfung, Springer-Verlag, Berlin.

[39] BASF SE, 2008, "Catamold ${ }^{\circledR}$ TZP-A - Data sheet, Processing Instructions, Product Specification."

[40] Lü, L., Fuh, J. Y. H., and Wong, Y.-S., 2013, Laser-Induced Materials and Processes for Rapid Prototyping, Springer Science+Business Media, New York.

[41] Wolfmeier, U., Schmidt, H., Heinrichs, F.-L., Michalczyk, G., Payer, W., Dietsche, W., Boehlke, K., Hohner, G., and Wildgruber, J., 2012, "Waxes," Ullmann's Encyclopedia of Industrial Chemistry, Wiley-VCH Verlag, Weinheim, Germany, pp. 111-172. 